\title{
A Spatial Agent-Based Model for the Simulation of Adults' Daily Walking Within a City
}

\author{
Yong Yang, PhD, Ana V. Diez Roux, PhD, MD, Amy H. Auchincloss, PhD, Daniel A. \\ Rodriguez, PhD, and Daniel G. Brown, PhD \\ Department of Epidemiology (Yang, Diez Roux), Center for Social Epidemiology and Population \\ Health, School of Natural Resources and Environment (Brown), University of Michigan, Ann \\ Arbor, Michigan; Department of Epidemiology and Biostatistics (Auchincloss), Drexel University, \\ Philadelphia, Pennsylvania; Department of City and Regional Planning (Rodriguez), University of \\ North Carolina, Chapel Hill, North Carolina
}

\begin{abstract}
Environmental effects on walking behavior have received attention in recent years because of the potential for policy interventions to increase population levels of walking. Most epidemiologic studies describe associations of walking behavior with environmental features. These analyses ignore the dynamic processes that shape walking behaviors. A spatial agent-based model (ABM) was developed to simulate peoples' walking behaviors within a city. Each individual was assigned properties such as age, SES, walking ability, attitude toward walking and a home location. Individuals perform different activities on a regular basis such as traveling for work, for shopping, and for recreation. Whether an individual walks and the amount she or he walks is a function distance to different activities and her or his walking ability and attitude toward walking. An individual's attitude toward walking evolves over time as a function of past experiences, walking of others along the walking route, limits on distances walked per day, and attitudes toward walking of the other individuals within her/his social network. The model was calibrated and used to examine the contributions of land use and safety to socioeconomic differences in walking. With further refinement and validation, ABMs may help to better understand the determinants of walking and identify the most promising interventions to increase walking.
\end{abstract}

\section{Introduction}

Environmental effects on walking have received increasing attention as a strategy to increase population levels of physical activity. ${ }^{1-3}$ Built environment characteristics found to be associated with walking include density of residents, land use mix, features of street design, and aesthetics. ${ }^{1,4-15}$ Greater safety, less violence, and greater social support for walking have also been found to be positively associated with walking. ${ }^{16-19}$

The majority of existing research has applied statistical models to observational data to estimate the associations of environmental characteristics with walking after controls for

\footnotetext{
(C) 2010 American Journal of Preventive Medicine. Published by Elsevier Inc. All rights reserved.

Address correspondence to: Ana V. Diez Roux, Department of Epidemiology, Center for Social Epidemiology and Population Health, University of Michigan, Ann Arbor MI, 48109. adiezrou@ umich.edu..

No financial disclosures were reported by the authors of this paper.

Publisher's Disclaimer: This is a PDF file of an unedited manuscript that has been accepted for publication. As a service to our customers we are providing this early version of the manuscript. The manuscript will undergo copyediting, typesetting, and review of the resulting proof before it is published in its final citable form. Please note that during the production process errors may be discovered which could affect the content, and all legal disclaimers that apply to the journal pertain.
} 
confounding variables. A limitation of this approach is the inability to completely account for the selection of people into neighborhoods. ${ }^{20,21}$ Another important limitation is that statistical models are unable to fully capture the dynamic set of relationships (including feedback loops and dynamic interactions among individuals, among environments, and between individuals and environments) through which environmental and personal attributes interact to shape walking behavior. Because population levels of walking emerge from the functioning of a system with various interacting components, the identification of the possible effects of a given policy or intervention requires understanding of the functioning of the system as a whole.

Agent-based models (ABMs) have received increasing attention as tools to investigate how dynamic processes shape the distribution of health outcomes, including the ways in which physical and social environments contribute to health-related behaviors. ${ }^{22,23} \mathrm{An} A B M$ is a computational model that can be used to simulate the actions and interactions of agents as well as the dynamic interactions between agents and their environments in order to gain understanding of the functioning of the system. ${ }^{24,25}$ These models can be used to investigate the impact of policy alternatives in the presence of nonlinear relationships and feedbacks. ABMs have been used to investigate the transmission of infectious diseases, the determinants of drinking and drug use, and the effects of healthy food availability on diet. $^{22,26-28}$ Although ABMs have been used to study pedestrian movement ${ }^{29-32}$ and there have been calls for greater use in the study of environmental effects on walking, ${ }^{33,34}$ applications in public health are still scarce.

An exploratory spatial agent-based model was developed to simulate people's walking behavior within a hypothetic city. The model was calibrated against existing population data. The model was then used to investigate how the spatial patterning of built and social environments (specifically land use and safety as illustrative examples) contributes to social inequalities in walking in the context of residential segregation by SES.

\section{Model Development}

The model was developed in Java and Repast. It is a time-discrete model with each time step being 1 day. For parsimony, the model includes adults on working days only (no weekends), seasonal variations and weather are ignored, a public transportation network is not included, and each individual is assumed to have a car.

The model represents a city of $64 \mathrm{~km}^{2}$, comparable in size to the city of Ann Arbor, MI. It is an $800 * 800$ grid space, where each cell of size $10 \mathrm{~m} * 10 \mathrm{~m}$ can be occupied by a specific location (i.e., a place with a social function) or empty. The city includes 200 groceries, 800 non-food shops, 1500 social places, 12000 workplaces and 60000 households (roughly based on Ann Arbor, http://www.census.gov/econ/cbp/index.html). The city has 400 equalsized neighborhoods, each composed of $40 * 40$ cells. Neighborhoods are assigned two environmental properties: safety and aesthetics. The adult population in the city includes 108000 individuals (48000 couples and 12000 single people). Each individual has a number of properties (Table 1). These properties are assigned at initiation, and for some properties the assignment varies depending on different scenarios.

Each individual is assigned a walking ability $A_{b}$ which is a function of the individual's age

and a random component: $A_{b}=U^{4}(0,1) \times\left(\frac{\operatorname{Min}(|137-\mathrm{Age}|, 100)}{100}\right)$, where, $U(0,1)$ is a random value 100 from the uniform distribution ranging between 0 and 1 . Walking ability is assumed to not vary between ages 18 and 37 years, but decreases linearly starting at age 38 years. In order to capture an individual's desire to walk, each individual is also assigned an 
attitude toward walking, defined as: $A_{t}=U^{3}(0,1)$. For $A_{b}$ and $A_{t}, U(0,1)$ powers of 3 or 4 are used to ensure that the distribution of each is skewed, as might be expected in reality. It is assumed that age and ability remain constant within the time frame of the model but attitudes toward walking evolve over time as a function of various feedbacks. The mean attitude for the whole population was assumed to be constant over time.

\section{Walking Behaviors}

Individuals can walk for three purposes: (1) to work; (2) for basic needs (such as food shopping, other shopping, and visits to social places); and (3) for leisure. These activities are assumed to happen with a certain probability over a given time interval (e.g., non-food shopping takes place every 4 days on average resulting in a daily probability of 0.25 ). In addition, there is a maximum distance that individuals will walk for each type of activity. Person-specific maximum distances are calculated as the product of maximum distances and the person-specific ability $\left(A_{b}\right)$. Parameters for these probabilities and thresholds (Table 1) were determined by calibrating the model against survey data as described below and in Appendix C (available online at www.ajpm-online.net).

Every day, all working people travel to their workplaces. If the distance between the person's household and the workplace is less than the person-specific maximum walking distance for that purpose, then the decision to walk is a random draw with probability equal to attitude $A_{t}$. All individuals routinely travel to grocery stores, non-food shops, and social places. Each day, the decision to travel to a grocery store or a non-food shop is a random draw with the corresponding daily probability of performing the activity. If there are groceries or non-food shops within the person-specific maximum distance around the person's household or workplace (with locations around households being searched before locations around workplaces), then the decision to walk to a randomly selected grocery or shop is a random draw with probability equal to $A_{t}$. Each day the decision to go to a social place is a random draw with probability noted in Table 1 . A social place is randomly selected from the whole city. If the distance between the social place and the household or workplace is less than the person-specific maximum distance for that purpose, the decision to walk is a random draw with probability equal to $A_{t}$. Each day, individuals also have the option of a leisure walk around their household. This choice is a random draw with probability equal to the product of the probability shown in Table 1 and attitude $A_{t}$. If the person decides to go for a walk, she/he will walk to any randomly selected cell with a distance in the range $75 \%-100 \%$ of the person-specific maximum walking distance.

\section{Feedbacks}

Feedbacks are implemented through updates to each person's attitude toward walking, which in turn affects how much they will walk in the subsequent day. At the end of each day, individuals update a small proportion $(a=0.001)$ of their attitude toward walking based on four feedbacks: (1) walking attitudes of family members and friends; (2) walking experience during that day which depends on the kinds of environments walked through; (3) the extent to which he/she observed others walking along the walking path that day and (4) the total amount walked during that day.

The feedback from family members and friends assumes that people's attitudes can be influenced by their social network ${ }^{35,36}$. For example, if individuals P1 and P2 make up a family, each day, their attitudes are updated as follows:

$$
A_{t}^{\prime}(\mathrm{P} 1)=(1-a) \times A_{t}(\mathrm{P} 1)+a A_{t}(\mathrm{P} 2)
$$




$$
A_{t}^{\prime}(\mathrm{P} 2)=(1-a) \times A_{t}(\mathrm{P} 2)+a A_{t}(\mathrm{P} 1)
$$

Similarly, for an individual $\mathrm{P}$, the attitude is influenced by the attitudes of her/his friends $\mathrm{F}$ as:

$$
A_{t}^{\prime}(\mathrm{P})=(1-a) \times A_{t}(\mathrm{P})+a \overline{A_{t}(\mathrm{~F})}
$$

A second feedback is based on each person's walking experience, assuming that a pleasant walking experience will encourage people to walk more. For each trip, an index $I_{e}$ is computed based on the levels of safety $(\bar{S})$ and aesthetic quality $(\bar{E})$ of all the cells along the route as:

$$
I_{e}=\frac{(S+U(-0.5,0.5))}{\bar{S}} \times \frac{(E+U(-0.5,0.5))}{\bar{E}}
$$

$S$ and $E$ are the lowest safety level and averaged aesthetic values of all cells along the walking route, respectively. A random component $U$ (a uniform distribution from -0.5 to 0.5 ) is added to both $S$ and $E$ to account for individual's subjectivity and perceptions. These values are scaled by dividing by the mean values of both dimensions ( $S$ and $E$ ) across the whole city.

The third feedback is from the density of other walkers along the walking route compared to the previous day. It is assumed that normative walking behaviors are influenced by relative shifts in observed behaviors, therefore this feedback is a function of the ratio of current walking density to previous walking density $I_{d}$. A value $>1$ results in a positive feedback to attitude and a value $<1$ results in a negative feedback.

The fourth feedback comes from the total amount walked by the person during that day. If an individual walked more than her/his maximum walking distance per day (defined as the maximum total walking distance per day $D_{\mathrm{a}}$ times her/his walking ability $A_{\mathrm{b}}$ ), her/his walking attitude will decrease. This feedback represents the negative feedback that may result from being tired after a long walk. If the distance walked during the day is $d$, then the index $I_{\mathrm{t}}$ is computed as follows:

$$
I_{t}=\operatorname{Min}\left(1, \frac{A_{b} D_{a}}{d}\right)
$$

At the end of each day, these feedbacks update the attitude toward walking as follows:

$$
A_{t}^{\prime}=A_{t} \times\left(1-a+a \overline{I_{e}}\right) \times\left(1-a+a \overline{I_{d}}\right) \times\left(1-a+a \overline{I_{t}}\right)
$$

\section{Scenarios}

In order to investigate the contributions of built and social environments to SES differences in walking, four scenarios were compared. All four have identical levels of residential segregation by SES, such that lower-SES households are located in the center of the city and higher-SES households are located in the periphery. The density of households was even over the city. The four scenarios (Appendix A, available online at www.ajpm-online.net) varied on two dimensions: (1) spatial distribution of non-household locations; and (2) spatial distribution of safety. The combination of the two dimensions generated four scenarios: RR: 
randomly distributed non-household locations and random safety level; RS: randomly distributed non-household location and lower safety level in the core; CR: more nonhousehold locations in the core and random safety level; and CS: more non-household locations and lower safety level in the core. For each scenario, the summaries are based on averages across 10 simulations. Each scenario was run for 10,000 time steps since graphical inspection showed that key model outputs (walking levels by SES) became relative stable after 6000-8000 time steps. Quantitative estimates also showed that between 6000 and 10,000 time steps, the difference between the maximum and minimum values was $<=2.6 \%$ of the maximum value, also indicating relative stability. The Brooks-Rubin-Gelman diagnostic was compatible with convergence of key model outputs. ${ }^{37}$

\section{Calibration}

The parameters in Table 1 were calibrated through an iterative process by which model output for scenario RR (with random distribution of non-household locations and safety) was compared to selected data from the 2001 National Household Travel Survey (NHTS, http://nhts.ornl.gov/). ${ }^{38}$ The NHTS characteristics used in the calibration are those shown in Table 2. The summaries used for calibration were based on the values of day 10,000 averaged across 10 simulations. Calibration was performed through an iterative process by which simulation results based on starting values for the parameter estimates were compared to NHTS characteristics, parameters adjusted to minimize any differences, simulations run again, and so on until simulated results matched the Table 2 NHTS data (Appendixes A-C, available online at www.ajpm-online.net, for more details).

\section{Model Assessment and Results}

Table 2 shows similarities between NHTS data and model predictions for the specific distributional characteristics used in the calibration. As expected from the calibration and the assumption in the model, for both NHTS data and the calibrated model, $35 \%-40 \%$ of people don't walk, most people (over 60\%) walk no more than 3 times a week, and only $10 \%-20 \%$ walk more than 7 times a week. The distribution of the distances of walking trips is highly skewed for both NHTS and model predictions: over 50\% of walking trips are less than one third of a mile and only about $11 \%-15 \%$ of walking trips are more than 1 mile. Although age-specific data were not used in the calibration, the model also generated age gradients in walking frequency and distance approximately similar to those reported for NHTS ${ }^{39}$. Model predictions also approximately matched other survey data in terms of average trips per day and mean and median distances per trip. ${ }^{40}$

Figure 1 shows walking trips per day by SES for each of the four scenarios. In scenario RR (random distribution of land use and safety), the difference in walking trips among SES groups was small (about 0.04 trips per day at the most), but higher-SES groups tended to walk slightly less than lower-SES groups. These small differences existed because higherSES groups were on the periphery of the grid so they had a smaller area within which to find suitable locations for walking. For scenario CR (central location of non-residential land use, random distribution of safety), there was a clear SES gradient in walking trips such that lower-SES groups walked more than higher-SES groups (mean trips per day 0.31 for SES 1 and 0.22 for SES 5). This was because, in scenario CR, lower-SES groups lived within the zone with higher density of non-household locations, thus, it was much easier for them to find locations within their walking distance. In RR and CR, levels of walking did not change over time because key drivers of feedback (safety and aesthetic quality along the walking route) were constant and not differentially distributed by SES.

The opposite pattern emerged in scenarios involving spatial patterning of safety. In scenario RS (random mix of land uses and spatial segregation of safety such that safety levels 
increase outwards) walking trips decreased over time in the lower-SES groups but increased over time in the higher-SES groups. However, in scenario CS, which combined spatial patterning of safety and land use such that the central areas (with lower SES) had greater mix of uses and lower safety level, the beneficial effects of proximity of destinations on walking in the lower-SES groups (as shown in scenario CR) was reduced over time because of the adverse effects of lack of safety. In the stable state, small differences in walking by SES remained in the CS scenario such that the lowest-SES groups walked slightly more than the highest-SES groups. Results from this scenario (which is likely the most realistic for many U.S. cities) were consistent with NHTS data ${ }^{39}$ (although SES gradients in NHTS data were not used in the calibration) showing only slightly more walking in the lower-than in the higher-income groups. Additional figures showing the spatial distribution of walking for different scenarios over time are available in Appendix B (available online at www.ajpm-online.net).

Figure 2 shows walking for different purposes by SES in scenario CS. Lower-SES groups walked more than the higher-SES groups for work (due to their proximity to work destinations), and less than the higher-SES groups within the neighborhood (due to the impact of safety). For basic needs trips, walking levels were similar across SES groups due to the counteracting effects of proximity to destinations and safety. These results were consistent with existing data showing that lower-income urban populations exhibit higher levels of walking for transportation and lower levels of walking for recreation, while higherincome urban populations have inverse patterns..$^{39,41}$

\section{Discussion}

By incorporating feedback mechanisms that allowed individuals to alter their walking behaviors in response to their social networks, their own previous experiences, and the prevalence of walking they encountered, this relatively simple model was able to generate patterns of walking behaviors that have been observed in empirical studies. The model allowed for feedbacks over time from both built and social environment features. In addition, walking for one purpose had effects on walking for other purposes (i.e., the model allows experiences in one realm of walking [e.g., walking to work] to influence other realms of walking [e.g., walking in the neighborhood]). The scenario analyses illustrate the utility of these models in understanding the processes driving differences in walking by SES. For example, results show that the co-spatial segregation of SES and safety, such that low-SES neighborhoods have a low safety level, results in less walking among the lower-SES groups even when SES is not spatially correlated with land-use mix (scenario RS). These differentials can become magnified over time due to feedback. The simulations also suggest that when lower-SES individuals live in areas with greater proximity to destinations, they tend to walk more than high-SES individuals (scenario CR), but this advantage can be neutralized when low-SES areas are also low in safety (scenario CS). Moreover, this simple interplay between land use and safety can create very different SES patterns for different types of walking. For example, in scenario CS, walking to work was higher in the lowerSES group, walking for leisure was higher in the higher-SES group, and walking for basic needs was not strongly patterned by SES.

Although the associations of greater mixed land use and more safety with more walking are a direct function of the model rules, the SES patterning of walking or the way in which this patterning changes over time as a function of the spatial co-location of SES, land use and safety, as well as the differential SES patterning of different types of walking, was not directly encoded in the model. The model contains no assumptions regarding SES differences in walking ability or attitudes at inception and was not calibrated to reflect any SES gradients. The model shows how these SES differences can emerge even in the context 
of similar starting walking preferences by SES and even in the absence of selection of people into neighborhoods based on walking preferences. The dynamics of these processes are very difficult to visualize or understand with statistical models alone, hence the utility of ABMs.

The model has substantial room for refinement. For example, gender differences were not modeled and aesthetic quality was assumed constant over space in all scenarios. The feedbacks are based on reasonable guesses and their relative magnitudes need refinement and validation (for example, the parameters associated with safety and aesthetics are arbitrary). The social networks are simplistic and the broader roles of social norms (e.g., through media influences) are not considered. Long-term positive feedbacks from habit formation were not considered. The model also does not yet incorporate feedbacks from walking to environmental features (i.e., endogeneity of environmental features). For example, just as mixed land use may promote walking, greater walking is likely to promote greater mixes of uses, as businesses locate in areas with heavy foot traffic. In addition cities may invest more in the aesthetics and safety of neighborhoods where people walk more.

The model was developed to be as simple as possible in order to begin to understand model properties before adding more complicated processes, but some simplifications may be problematic. One assumption in the model is that all trips always begin and end at the household or workplace but individuals may combine trips ${ }^{42}$. Residents with low levels of access to destinations combine more trips, clusters of destinations serve as "activity centers" that attract people for multiple reasons, $7,43,44$ and people may be more likely to walk to an "activity center" where several errands can be accomplished along the same trip. ${ }^{45}$ Different transportation modes may also affect each other in complex ways. For example, those who regularly walk long distances to work may not be inclined to walk in their neighborhood. Conversely, it is plausible that traveling by car to work or shopping may leave more free time to walk in the neighborhood. Calibration is a challenging process in ABMs in terms of the data to be used in the calibration and the process to be followed ${ }^{46}$. A preliminary calibration was performed by adjusting selected parameter values (for which no empirical data were available) so that summaries of model output were consistent with selected empirical data from NHTS. Discrepancies between model outputs and empirical data (e.g., median distance in Table 2) may imply the need for further calibration or modification of model assumptions. Also, replication of selected existing patterns does not necessarily imply that underlying processes are correctly specified. A valid model requires that data inputs be based on existing data whenever possible, but in developing this simple model, it became quickly apparent that there is a dearth of data on which to base model inputs. For example, evidence ${ }^{47}$ suggests that dog owners walk more than non-owners but the magnitude of the difference is not clear. Growing interest in developing these types of models may serve as an impetus to the collection of this type of data.

By being explicit about the ways in which features of the social and physical environment affect attitudes toward walking and the actual probability of walking and distance walked, ABMs can formalize the understanding of environmental effects on walking. Once a reasonably realistic model is developed and is functionally understood, it can be used to evaluate the impact of policies and interventions. For example, after further refinement, scenario CS could be used to evaluate the impact of promoting mixed land use and or increasing safety on population levels of walking or on SES difference in walking.

Importantly, conclusions about the impact of these interventions would be drawn taking into consideration dynamic relations and feedbacks, rather than based on the extrapolation of the simplified relationship between these attributes and walking in regression models. Together with other methods, ABMs may help to better understand the determinants of walking and identify the most promising interventions to increase walking and physical activity. 


\section{Supplementary Material}

Refer to Web version on PubMed Central for supplementary material.

\section{Acknowledgments}

Support for this work was received from the NIH (R24 HD047861), National Heart, Lung and Blood Institute (R01 HL071759), and the Robert Wood Johnson Foundation Health and Society Scholars program.

\section{References}

1. Owen N, Humpel N, Leslie E, Bauman A, Sallis JF. Understanding Environmental Influences on Walking: Review and Research Agenda. American Journal of Preventive Medicine. 2004; 27(1): 67-76. [PubMed: 15212778]

2. Saelens B, Sallis J, Frank L. Environmental correlates of walking and cycling: Findings from the transportation, urban design, and planning literatures. Ann Behav Med. 2003; 25:80-91. [PubMed: 12704009]

3. Brownson RC, Kelly CM, Eyler AA, Carnoske C, Gros L, Handy SL, Maddock JE, Pluto D, Ritacco BA, Sallis JF, Schmid TL. Environmental and policy approaches for promoting physical activity in the U.S.: a research agenda. Journal of Physical Activity and Health. 2008; 5:488-503. [PubMed: 18648115]

4. Transportation Research Board. TRB Special Report 282: Does the Built Environment Influence Physical Activity?. Examing the Evidence. 2005.

5. Handy SL, Boarnet MG, Ewing R, Killingsworth RE. How the built environment affects physical activity views from urban planning. American Journal of Preventive Medicine. 2002; 23(2S):64-73. [PubMed: 12133739]

6. Handy, S. Critical Assessment of the Literature on the Relationships Among Transportation, Land Use, and Physical Activity, Prepared for the Committee on Physical Activity, Health, Transportation, and Land Use. 2004.

7. Frank, LD.; Engelke, PO.; Schmid, TL. Health and Community Design: the Impact of the Built Environment on Physical Activity. Island Press; Washington, DC: 2003.

8. Frank LD, Kerr J, Sallis JF, Miles R, Chapman J. A hierarchy of sociodemographic and environmental correlates of walking and obesity. Preventive Medicine. 2008; 47:172-178. [PubMed: 18565576]

9. Berke EM, Koepsell TD, Moudon AV, Hoskins RE, Larson EB. Association of the Built Environment With Physical Activity and Obesity in Older Persons. American Journal of Public Health. 2007; 97(3):486-492. [PubMed: 17267713]

10. Brownson RC, Baker EA, Housemann RA, Brennan LK, Bacak SJ. Environmental and policy determinants of physical activity in the U.S. American Journal of Public Health. 2001; 91(12): 1995-2003. [PubMed: 11726382]

11. Heath GW, Brownson RC, Kruger J, Miles R, Powell KE, Ramsey LT, Services tTFoCP. The Effectiveness of Urban Design and and Use and Transport Policies and Practices to Increase Physical Activity: A Systematic Review. Journal of Physical Activity and Health. 2006; 3(S1):S55-S76.

12. Humpel N, Owen N, Leslie E. Environmental Factors Associated with Adults' Participation in Physical Activity: A Review. American Journal of Preventive Medicine. 2002; 22(3):188-99. [PubMed: 11897464]

13. Lee C, Moudon AV. Physical Activity and Environment Research in the Health Field: Implications for Urban and Transportation Planning Practice and Research. Journal of Planning Literature. 2004; 19(147):147-181.

14. Saelens BE, Sallis JF, Frank LD. Environmental Correlates of Walking and Cycling: Findings from the Transportation, Urban Design, and Planning Literatures. Annals of Behavioral Medicine. 2003; 25(2):80-91. [PubMed: 12704009]

15. Saelens BE, Handy SL. Built Environment Correlates of Walking: A Review. Medicine \& Science in Sports \& Exercise. 2008; 40(7):S550-S566. Supplement(1). [PubMed: 18562973] 
16. Giles-Corti B, Donovan RJ. Relative Influences of Individual, Social Environmental, and Physical Environmental Correlates of Walking. American Journal of Public Health. 2003; 93(9):1583-9. [PubMed: 12948984]

17. Giles-Corti B, Donovan RJ. The relative influence of individual, social and physical environment determinants of physical activity. Social Science \& Medicine. 2002; 54:1793-1812. [PubMed: 12113436]

18. Ball K, Timperio A, Salmon J, Giles-Corti B, Roberts R, Crawford D. Personal, social and environmental determinants of educational inequalities in walking: a multilevel study. Journal of Epidemiology and Community Health. 2007; 61:108-114. [PubMed: 17234868]

19. Eyler AA, Brownson RC, Bacak SJ, Housemann RA. The epidemiology of walking for physical activity in the U.S. Medicine \& Science in Sports \& Exercise. 2003; 35(9):1529-36. [PubMed: 12972873]

20. Oakes JM. Commentary: Advancing neighbourhood-effects research—selection, inferential support, and structural confounding. International Journal of Epidemiology. 2006; 35(3):643-647. [PubMed: 16556642]

21. Handy S, Cao X, Mokhtarian PL. Self-selection in the relationship between the built environment and walking. Journal of the American Planning Association. 2006; 72(1):55.

22. Auchincloss A, Diez-Roux A. A new tool for epidemiology: the usefulness of dynamic-agent models in understanding place effects on health. American Journal of Epidemiology. 2008; 168(1): 1-8. [PubMed: 18480064]

23. Galea S, Riddle M, Kaplan GA. Causal thinking and complex system approaches in epidemiology. Int. J. Epidemiol. 2009:dyp296.

24. Axtell R, Epstein JM. Agent-Based Modeling: Understanding Our Creations. The Bulletin of The Santa Fe Institute. 1994 Winter;:28-32.

25. Bonabeau E. Agent-based modeling: Methods and techniques for simulating human systems. PNAS. 2002; 99(90003):7280-7287. [PubMed: 12011407]

26. Yang Y, Atkinson PM, Ettema D. Simulation of Infectious Disease Transmission within a City: the Application of ISTAM to Eemnes by Role-based AB Simulation. Journal of the Royal Society Interface. 2008; 5:759-772.

27. Galea S, Hall C, Kaplan GA. Social epidemiology and complex system dynamic modelling as applied to health behaviour and drug use research. International Journal of Drug Policy. 2009; 20(3):209-216. [PubMed: 18930649]

28. Gorman DM, Mezic J, Mezic I, Gruenewald PJ. Agent-Based Modeling of Drinking Behavior: A Preliminary Model and Potential Applications to Theory and Practice. Am J Public Health. 2006; 96(11):2055-2060. [PubMed: 17018835]

29. Willis A, Gjersoe N, Havard C, Kerridge RK Jon. Human movement behaviour in urban spaces: implications for the design and modelling of effective pedestrian environments. Environment and Planning B: Planning and Design. 2004; 31(6):805-828.

30. Turner A, Penn A. Encoding natural movement as an agent-based system: an investigation into human pedestrian behaviour in the built environment. Environment and Planning B: Planning and Design. 2002; 29(4):473-490.

31. Batty, M. Agent-Based Pedestrian Modelling. In: Longley, PA.; Batty, M., editors. Advanced Spatial Analysis: The CASA Book of GIS Redlands. ESRI Press; USA: 2003.

32. Haklay M, O'Sullivan D, Thurstain-Goodwin M, Schelhorn T. "So go downtown": simulating pedestrian movement in town centres. Environment and Planning B: Planning and Design. 2001; 28(3):343-359.

33. Saarloos D, Kim J-E, Timmermans H. The Built Environment and Health: Introducing Individual Space-Time Behavior. International Journal of Environmental Research and Public Health. 2009; 6:1724-1743. [PubMed: 19578457]

34. King AC, Satariano WA, Marti J, Zhu W. Multilevel Modeling of Walking Behavior: Advances in Understanding the Interactions of People, Place, and Time. Medicine \& Science in Sports \& Exercise. 2008; 40(7 Supple):S584-93. [PubMed: 18562976]

35. Steptoe A, Diez-Roux A. Happiness, social networks, and health. BMJ. 2008; 337:a2781. (dec04_2). [PubMed: 19056790] 
36. Christakis NA, Fowler JH. The Spread of Obesity in a Large Social Network over 32 Years. N Engl J Med. 2007; 357(4):370-379. [PubMed: 17652652]

37. Brooks SP, Gelman A. General methods for monitoring convergence of iterative simulations. Journal of Computational and Graphical Statistics. 1998; 7(4):434-455.

38. Agrawal AW, Schimek P. Extent and correlates of walking in the U.S. Transportation Research Part D: Transport and Environment. 2007; 12(8):548-563.

39. Pucher J, Renne JL. Socioeconomics of Urban Travel: Evidence from the 2001 NHTS. Transportation Quarterly. 2003; 57(3):49-77.

40. Tudor-Locke C, Ham SA. Walking behaviors reported in the American Time Use Survey $2003-$ 2005. Journal of Physical Activity and Health. 2008; 5(5):633-47. [PubMed: 18820341]

41. Kruger J, Ham SA, Berrigan D, Ballard-Barbash R. Prevalence of transportation and leisure walking among U.S. adults. Preventive Medicine. 2008; 47(3):329-34. [PubMed: 18445507]

42. Krizek KJ. Neighborhood services, trip purpose, and tour-based travel. Transportation. 2003; 30(4):387-410.

43. Sallis JF. Angels in the details: comment on "The relationship between destination proximity, destination mix and physical activity behaviors". Preventive Medicine. 2008; 46(1):6-7. [PubMed: 17467781]

44. Moudon AV, Lee C, Cheadle AD, Garvin C, Johnson D, Schmid TL, Weathers RD, Lin L. Operational Definitions of Walkable Neighborhood: Theoretical and Empirical Insights. Journal of Physical Activity and Health. 2006; 3(S1):S99-S117.

45. McCormack GR, Giles-Corti B, Bulsara M. The relationship between destination proximity, destination mix and physical activity behaviors. Preventive Medicine. 2008; 46(1):33-40. [PubMed: 17481721]

46. Cioffi-Revilla C. Invariance and universality in social agent-based simulations. Proceedings of the U.S. National Academy of Sciences. 2002; 99(Suppl 3):7314-7316.

47. Cutt H, Giles-Corti B, Knuiman M, Burke V. Dog ownership, health and physical activity: A critical review of the literature. Health \& Place. 2007; 13(1):261-272. [PubMed: 16503185] 


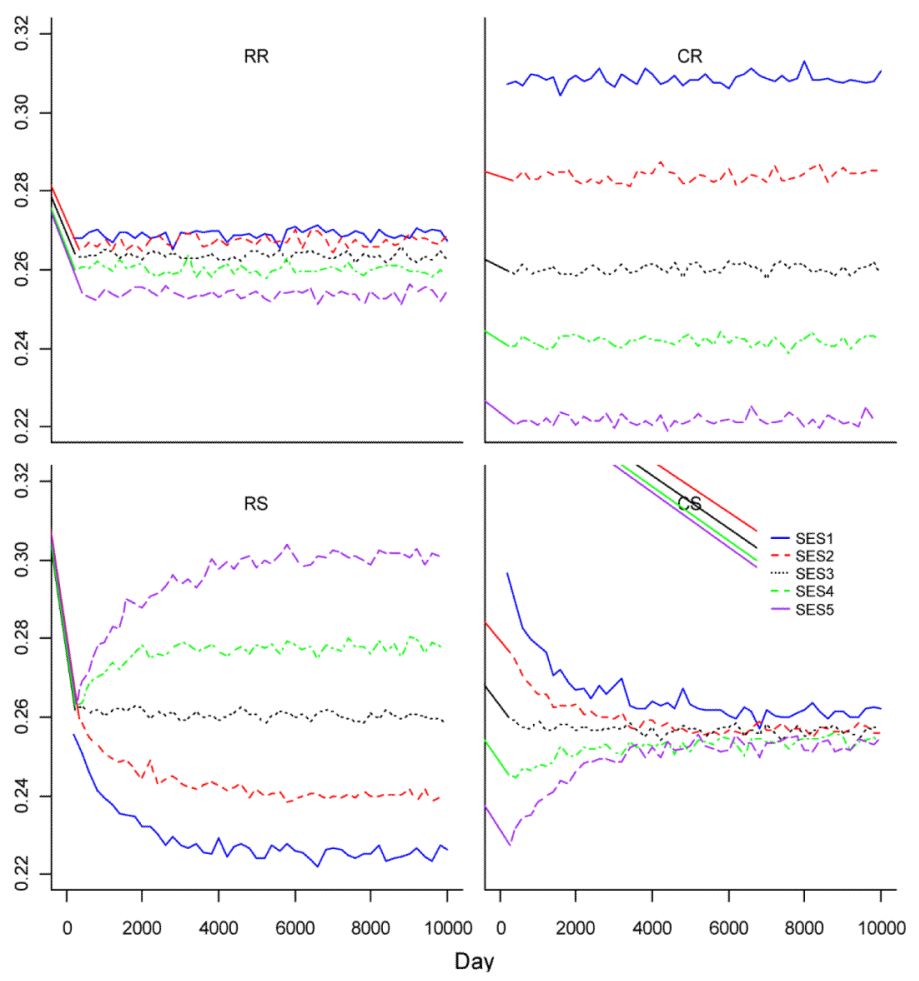

Figure 1.

Average walking trips per day per person for different SES groups over time for four scenarios CR, more non-household locations in the core and random safety level; CS, more non-household locations and lower safety level in the core; RR, randomly distributed nonhousehold locations and random safety level; RS, randomly distributed non-household location and lower safety level in the core 


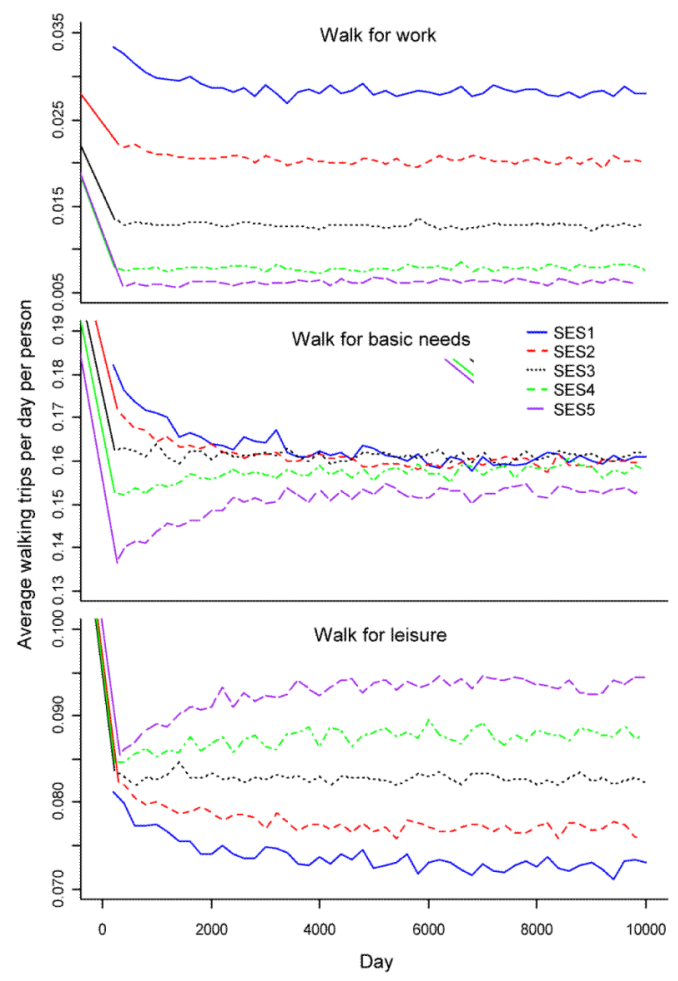

Figure 2.

Average walking trips per day per person for different purposes and for different SES groups over time in the CS scenario CS, more non-household locations and lower safety level in the core 
Table 1

Properties of individuals and selected model parameters

\begin{tabular}{|l|l|}
\hline $\begin{array}{l}\text { Individual- } \\
\text { level } \\
\text { properties }\end{array}$ & Values and meaning \\
\hline Gender & Assigned as male or female with equal probability \\
\hline Age & $\begin{array}{l}\text { Random integer from the uniform distribution ranging between } 18 \text { and } 87 \text { years, the } \\
\text { difference between a couple is no more than 3 years }\end{array}$ \\
\hline SES & $\begin{array}{l}\text { Integer value ranging between 1 and 5, with higher values indicating higher SES. } \\
\text { Members of a family are assumed to have the same SES. In select scenarios SES is } \\
\text { assumed to be positively correlated with increasing distance from the city's center. }\end{array}$ \\
\hline Family size & Family size can be 1 (with probability of 20\%) or 2 (with probability of 80\%) \\
\hline Friends & $\begin{array}{l}\text { Each individual has 3 to 5 friends who can influence her/his walking attitude, } \\
\text { randomly selected from the people with the same or similar SES value (difference no } \\
\text { more than 2) }\end{array}$ \\
\hline $\begin{array}{l}\text { Dog } \\
\text { ownership }\end{array}$ & $\begin{array}{l}\text { Each individual has a 20\% probability of having a dog (dog owners have a higher } \\
\text { probably of walking within the neighborhood) }\end{array}$ \\
\hline Household & $\begin{array}{l}\text { Each person is randomly assigned to a household (except in scenarios involving } \\
\text { residential segregation by SES). }\end{array}$ \\
\hline $\begin{array}{l}\text { Work and } \\
\text { Workplace }\end{array}$ & $\begin{array}{l}\text { If age <=69 years, the probability of working is 95\%; people aged }>69 \text { years are } \\
\text { assumed to not work. Working people are randomly assigned a workplace in the city. } \\
\text { This can be a grocery store, a non-food shop, a social place or another workplace in } \\
\text { the city. }\end{array}$ \\
\hline $\begin{array}{l}\text { Walking } \\
\left.\text { ability ( } \mathrm{A}_{\mathrm{b}}\right)\end{array}$ & $\begin{array}{l}\text { Value ranges from 0 to 1, the higher the value, the longer distance an individual can } \\
\text { walk }\end{array}$ \\
\hline $\begin{array}{l}\text { Attitude } \\
\text { toward } \\
\text { walking }\left(\mathrm{A}_{\mathrm{t}}\right)\end{array}$ & $\begin{array}{l}\text { Value ranges from 0 to 1, the higher the value, the higher probability an individual } \\
\text { will walk }\end{array}$ \\
\hline
\end{tabular}

\begin{tabular}{|l|l|l|}
\hline Calibrated model parameters & \\
\hline Activity & $\begin{array}{l}\text { Daily probability of performing the } \\
\text { activity }\end{array}$ & $\begin{array}{l}\text { Maximum walking distance for the } \\
\text { activity (miles) }\end{array}$ \\
\hline Work $a$ & 1 for individuals with a job; 0 for others & 1.125 \\
\hline $\begin{array}{l}\text { Food } \\
\text { shopping }\end{array}$ & 0.4 & 2 \\
\hline $\begin{array}{l}\text { Other } \\
\text { shopping }\end{array}$ & 0.25 & 1.5 \\
\hline $\begin{array}{l}\text { Visiting a } \\
\text { social place }\end{array}$ & 0.2 & 2.5 \\
\hline $\begin{array}{l}\text { Leisure } \\
\text { within } \\
\text { neighborhood }\end{array}$ & 0.33 & 5.5 \\
\hline
\end{tabular}

${ }^{a}$ Only among employed 


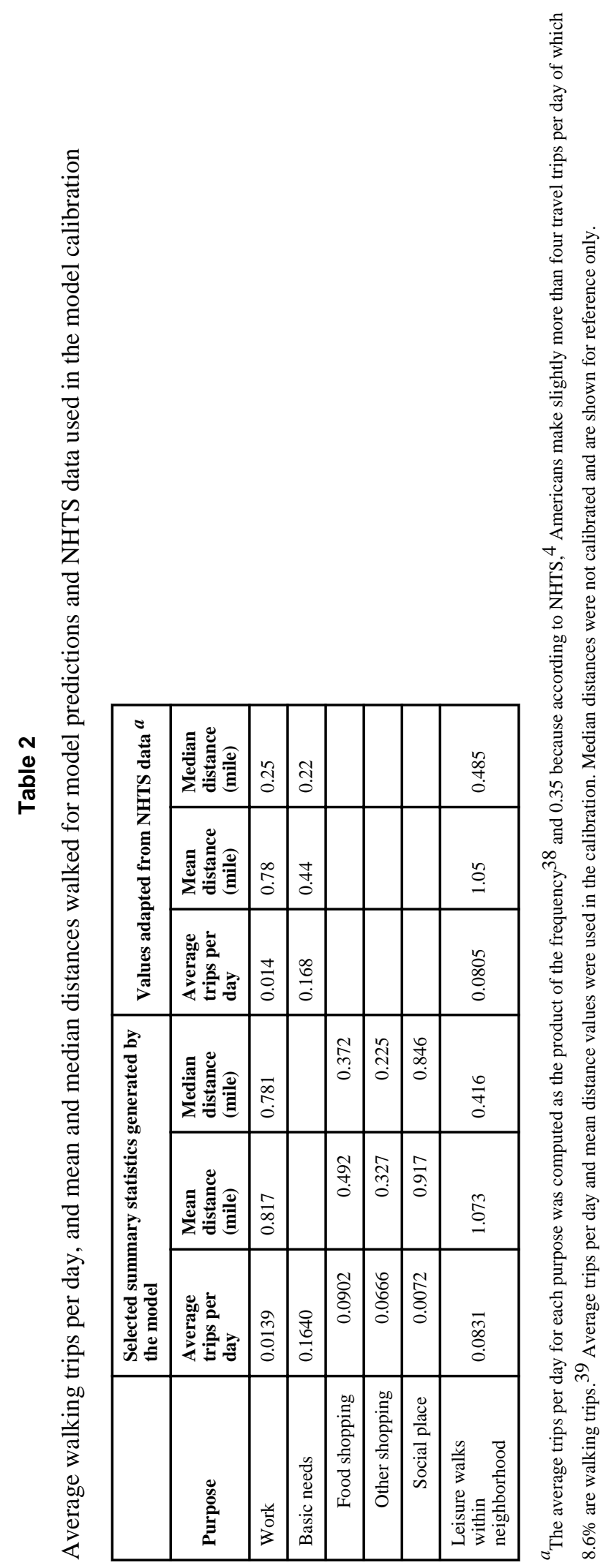

Am J Prev Med. Author manuscript; available in PMC 2012 March 17. 